\title{
Helminth infection during pregnancy: insights from evolutionary ecology
}

\author{
This article was published in the following Dove Press journal: \\ International Journal of Women's Health \\ II November 2016 \\ Number of times this article has been viewed
}

\author{
Aaron D Blackwell \\ Department of Anthropology, \\ University of California, Santa \\ Barbara, Santa Barbara, CA, USA
}

Correspondence: Aaron D Blackwell Department of Anthropology, University of California, Santa Barbara, CA 93106-3210, USA

Tel +l 8058934234

Fax +l 8058938707

Email blackwell@anth.ucsb.edu

\begin{abstract}
Helminths are parasitic nematodes and trematodes, grouped together because of morphological similarities and commonalities in the effects infections have on hosts. These include complications such as anemia and biasing of immune responses, which can alter susceptibility for other diseases. For pregnant women, these complications might have implications for pregnancy outcomes or neonatal health. Here, I review studies of helminth infections during pregnancy, and ask the following questions: Do helminths affect maternal health or pregnancy outcomes? Are there consequences of maternal infection for infants? What are the effects of antihelminth treatment during pregnancy? The evidence suggests that the answers to these questions depend on the particular helminth species in question, maternal nutritional status, and the presence or absence of comorbid infection with other species, such as malaria. Moreover, there may also be unexpected consequences of treatment, as maternal infections can affect the priming of infant immune systems, with potential effects on infants later in life. These complex interactions suggest that a consideration of the evolutionary history of human-helminth interactions, as well as the ecological context of infections, can help to clarify an understanding of these host-parasite interactions and provide direction for future investigations.
\end{abstract}

Keywords: review, helminths, pregnancy, filariasis, schistosomiasis

\section{Introduction}

Helminths are various species of nematode and trematode worms that infect more than a billion people worldwide. ${ }^{1}$ Though quite diverse (Box 1), helminths share common features, such as life cycles that require life stages outside of the primary host and complex effects on host immunity. ${ }^{2}$ Helminths can be asymptomatic or can cause disease in their hosts, including anemia, nutritional deficiencies, changes in immunity, and more serious complications, such as elephantiasis and organ blockages. ${ }^{3-12}$ Since these complications might have consequences for pregnant women or developing fetuses, the World Health Organization has recommended that pregnant women be treated for helminth infections. ${ }^{3}$ However, these recommendations were made largely in the absence of adequate clinical trials, and more recent studies have begun to recognize that helminth infection and helminth treatment can have complex effects on mothers and infants (Tables 1-3). These effects include alterations in immunity, with implications for the development of allergy and autoimmune disease, as well as resistance to other infections.

In this review, I first discuss the effects of helminths on mothers and infants during pregnancy, as well as the results of trials examining the effects of helminth treatment. I then discuss these findings in the context of evolutionary ecology and the history of human-helminth interactions. 
Box I Three kinds of helminths

The term helminth is a non-taxonomical term used to refer to several species of infectious trematodes and nematodes. For the purposes of this review, I discuss three broad groups of helminths that infect humans.

Soil-transmitted nematodes are transmitted to humans via a life stage occurring in soil. Soil-transmitted helminths reside in the intestine, where they produce eggs that are excreted in the feces. Hookworm is a common name referring to two distinct species, Necator americanus and Ancylostoma duodenale. These two species of hookworms cannot be distinguished by standard fecal egg counts, and so are frequently referred to simply as hookworms. Hookworm larvae infect their hosts by penetrating through the skin, generally through the feet. ${ }^{7}$ Ascaris lumbricoides or roundworm is the largest of the infectious nematodes. A. lumbricoides is transmitted by ingestion of eggs. ${ }^{8}$ After infection, both hookworm and roundworm larvae migrate into the vasculature, to the heart, and then into the lungs. From the lungs, they are coughed up and swallowed, entering the gastrointestinal tract where they develop into adults. ${ }^{7.8}$ Other soil-transmitted nematodes such as Strongyloides stercoralis (threadworm) have complex life cycles that involve free-living stages and less directed tissue migration, ${ }^{9}$ while some nematodes, such as Trichuris trichiura (whipworm), infect the gastrointestinal tract directly, without tissue migration, when eggs are ingested. ${ }^{10}$

Filarial nematodes are smaller than soil-transmitted nematodes. Larvae called microfilariae are transmitted by biting insects from host to host. Wuchereria bancrofti is transmitted by mosquitos and infects the lymphatic system. Complications can include elephantiasis. Onchocerca volvulus is transmitted by black flies and infects subcutaneous tissue. Onchocerciasis (river blindness) is caused when microfilariae migrate into the eye. Mansonella perstans is transmitted by midges and infects serous body cavities, usually producing only mild symptoms."

Schistosomes, also referred to as blood flukes, are trematodes that infect either the mesenteric veins around the intestine or the venous plexus around the bladder. Schistosomes secrete eggs into the intestine or bladder, which are excreted into water. Eggs hatch, and larvae infect snails which serve as intermediary hosts. Motile larvae called cercariae leave the snails to seek out human hosts which they infect through the skin when humans come into contact with infected water. ${ }^{12}$ The most serious complications of schistosome infections occur when the host immune system forms granulomas around eggs, which can lead to obstructions in the intestine, liver, kidney, or other areas. The most common species are Schistosoma mansoni, Schistosoma haematobium, and Schistosoma japonicum.

\section{Review methodology}

Articles pertaining to infection with helminths during pregnancy were searched for on Google Scholar and Web of Science using the terms ("pregnancy" OR "birth") AND ("helminth" OR the name of one of the helminth species mentioned in Box 1, eg, "Ascaris lumbricoides"). Google Scholar was also used to identify relevant articles citing the articles identified by the initial search. Additional articles cited within the articles found in the search were also included, as were articles previously known to the author through past research, for example, the articles cited in my past study. ${ }^{4}$ Other authors have conducted recent meta-analyses of helminth treatment during pregnancy, ${ }^{5,6}$ while for topics other than treatment, the identified articles reflected substantial heterogeneity in research context and methods, or were very few in number. Thus, in order to provide as broad an overview as possible, formal inclusion and exclusion criteria were not applied to the located articles, and instead, all articles with relevant and interpretable findings are discussed.

\section{Intersections between pregnancy and helminth infection}

Helminths and developing fetuses can both be thought of as foreign, immunologically distinct organisms living in a

Table I Effects of soil-transmitted nematodes during pregnancy

\begin{tabular}{|c|c|c|c|c|}
\hline Species (common name) & $\begin{array}{l}\text { Adult worm } \\
\text { infection site }\end{array}$ & $\begin{array}{l}\text { Direct effects } \\
\text { on host }\end{array}$ & Effects on coinfection risk & Effects on infant \\
\hline $\begin{array}{l}\text { Necator americanus/ } \\
\text { Ancylostoma duodenale } \\
\text { (hookworm) }\end{array}$ & Small intestine & $\begin{array}{l}\text { Anemia }^{34-38,63,67,111} \\
\text { Lower IFN- } \gamma \text { response to } \\
\text { tuberculosis lysate }^{76} \\
\text { Reduced maternal fertility }\end{array}$ & $\begin{array}{l}\text { Higher malaria parasitemia } \\
\text { or prevalence } \\
\text { Higher HIV viral load } \\
\text { Heduced giardia prevalence } \\
\text { Red7 }\end{array}$ & $\begin{array}{l}\text { Higher IFN- } \gamma \text { response to } \\
\text { tuberculosis lysate }^{76} \\
\text { Lower rate of eczema }^{81} \\
\text { Lower odds of low birth weight with } \\
\text { infection }^{66} \\
\text { Poorer motor skills and lower } \\
\text { cognitive ability } \\
\text { Increased risk of childhood malaria }\end{array}$ \\
\hline $\begin{array}{l}\text { Ascaris lumbricoides } \\
\text { (roundworm) }\end{array}$ & Small intestine & $\begin{array}{l}\text { Often asymptomatic } \\
\text { Occasional anemia }{ }^{39} \\
\text { Increase in geophagy }{ }^{120} \\
\text { Higher maternal fertility }\end{array}$ & $\begin{array}{l}\text { Increased odds of Plasmodium } \\
\text { falciparum }^{50} \\
\text { Higher malaria prevalence }^{49}\end{array}$ & $\begin{array}{l}\text { Possibility of limited maternal-infant } \\
\text { transmission }^{71}\end{array}$ \\
\hline $\begin{array}{l}\text { Trichuris trichiura } \\
\text { (whipworm) }\end{array}$ & Large intestine & $\begin{array}{l}\text { Often asymptomatic, but } \\
\text { may cause abdominal pain } \\
\text { and anemia }\end{array}$ & $\begin{array}{l}\text { Increased odds of } \\
\text { P. falciparum } \\
\text { Higher HIV viral load }\end{array}$ & $\begin{array}{l}\text { Increase in low weight for } \\
\text { gestational age, but only in } \\
\text { undernourished mothers }\end{array}$ \\
\hline
\end{tabular}

Abbreviations: IFN- $\gamma$, interferon- $\gamma$; HIV, human immunodeficiency virus. 
Table 2 Effects of filarial nematodes during pregnancy

\begin{tabular}{|c|c|c|c|c|}
\hline Species & $\begin{array}{l}\text { Adult worm } \\
\text { infection site }\end{array}$ & $\begin{array}{l}\text { Direct effects } \\
\text { on host }\end{array}$ & Effects on coinfection & Effects on infant \\
\hline Wuchereria bancrofti & Lymphatic system & $\begin{array}{l}\text { Elephantiasis in } \\
\text { hyperresponsive individuals }\end{array}$ & $\begin{array}{l}\text { Little effect on HIVI21 } \\
\text { Unclear or mixed } \\
\text { effects on malaria }^{48}\end{array}$ & $\begin{array}{l}\text { Reduced odds of low birth weight with infection } \\
\text { Increased maternal/infant HIV transmission } \\
\text { Helminth-specific T-cell immunity and lower } \\
\text { IFN- } \gamma \text { response to tuberculosis } \\
\text { Lower response to } W \text {. bancrofti antigen } \\
\text { I7-19 years later }{ }^{85} \\
\text { Increased infection in tolerant, but not sensitized } \\
\text { children }^{74} \\
\text { Increased infection in children of infected } \\
\text { mothers }^{80,84}\end{array}$ \\
\hline Onchocerca volvulus & Subcutaneous tissue & $\begin{array}{l}\text { Onchocerciasis } \\
\text { (river blindness) }\end{array}$ & & $\begin{array}{l}\text { Children of infected mothers are also more likely } \\
\text { to be infected } \\
\text { Children of infected mothers have higher } \mathrm{T}_{\mathrm{H}} 2 \\
\text { cytokines and lower } \mathrm{T}_{\mathrm{H}} \mathrm{I} \text { cytokines }{ }^{78} \\
\text { Possible in utero transmission }\end{array}$ \\
\hline Mansonella perstans & Serous body cavities & $\begin{array}{l}\text { Generally mild or } \\
\text { asymptomatic, but } \\
\text { occasional symptoms } \\
\text { may occur }{ }^{122}\end{array}$ & $\begin{array}{l}\text { Higher malaria } \\
\text { parasitemia }^{36} \text { and } \\
\text { prevalence }^{47}\end{array}$ & $\begin{array}{l}\text { Maternal infection associated with higher IL-I0 } \\
\text { to BCG and tetanus immunogens }{ }^{75}\end{array}$ \\
\hline
\end{tabular}

Abbreviations: IFN- $\gamma$, interferon- $\gamma$; IL-10, interleukin-I0; BCG, bacillus Calmette-Guérin; HIV, human immunodeficiency virus.

maternal body. Both helminths and pregnancy are associated with changes in maternal immunity and physiology. Normal pregnancy is associated with shifts in immunity toward the production of type $2\left(\mathrm{~T}_{\mathrm{H}} 2\right)$ responses, which may increase tolerance of an immunologically distinct fetus. ${ }^{13,14}$ Helminths cause similar biases in immunity toward $\mathrm{T}_{\mathrm{H}} 2$ responses, ${ }^{2,15}$ and also affect regulatory $\mathrm{T}$-cells, modulating both $\mathrm{T}_{\mathrm{H}} 1$ and $\mathrm{T}_{\mathrm{H}} 2$ responses. ${ }^{16,17}$ Whether these changes reflect adaptive host responses, parasite manipulation, or some combination remains unclear, ${ }^{2}$ particularly since for helminths, the most adaptive host response may be to develop tolerance rather than mount an excessive immune attack. ${ }^{18,19}$ However, the similarity between the immune responses to helminths and those induced in pregnancy suggests that similar mechanisms of tolerance may be invoked, and that helminths may have evolved to utilize similar mechanisms for avoiding maternal immune responses that are used by a human fetus.

Some evidence in animals suggests that pregnant individuals might be at a greater risk for helminth infections than nonpregnant individuals. ${ }^{20,21}$ However, in humans, there is little evidence that pregnancy alters transmission risks for helminths, ${ }^{4,22}$ though a few results are suggestive of this possibility. ${ }^{23}$ Despite this, helminths and pregnancy might have synergistic effects on other health outcomes. Helminths and pregnancy both require nutritional and energetic resources such as iron, glucose, lipids, and other molecules critical for

Table 3 Effects of Schistosoma during pregnancy

\begin{tabular}{|c|c|c|c|c|}
\hline Species & $\begin{array}{l}\text { Adult worm } \\
\text { infection site }\end{array}$ & $\begin{array}{l}\text { Direct effects } \\
\text { on host }\end{array}$ & Effects on coinfection risk & Effects on infant \\
\hline Schistosoma mansoni & Mesenteric veins & $\begin{array}{l}\text { Intestinal schistosomiasis } \\
\text { Anemia and undernutrition } \\
\text { Lower serum cholesterol }^{124}\end{array}$ & $\begin{array}{l}\text { No effect on malaria }{ }^{47} \\
\text { No effect on HIV viral load } \\
\text { Increased odds of coinfection } \\
\text { with Schistosoma haematobium } \\
\text { or hookworm }\end{array}$ & $\begin{array}{l}\text { Increase in total IgE and tuberculosis- } \\
\text { specific IgG transfer from mothers. } \\
\text { Lower IFN- } \gamma \text { response to tuberculosis } \\
\text { lysate, but no change in IL- } 4 \\
\text { response }^{77}\end{array}$ \\
\hline $\begin{array}{l}\text { Schistosoma } \\
\text { haematobium }\end{array}$ & $\begin{array}{l}\text { Venous plexus } \\
\text { around the bladder }\end{array}$ & $\begin{array}{l}\text { Urinary schistosomiasis } \\
\text { Anemia }^{110}\end{array}$ & $\begin{array}{l}\text { Increased odds of coinfection } \\
\text { with Schistosoma mansoni or } \\
\text { hookworm }{ }^{125}\end{array}$ & $\begin{array}{l}\text { Reduced odds of low birth weight } \\
\text { with infection } \\
\text { Increase in preterm deliveries and } \\
\text { lower birth weight in preterm } \\
\text { deliveries }^{126}\end{array}$ \\
\hline $\begin{array}{l}\text { Schistosoma } \\
\text { japonicum }\end{array}$ & Mesenteric veins & $\begin{array}{l}\text { Intestinal schistosomiasis } \\
\text { Anemia } 110\end{array}$ & & Possible lower birth weight ${ }^{127}$ \\
\hline
\end{tabular}

Abbreviations: IgE, immunoglobulin E; IgG, immunoglobulin G; IFN- $\gamma$, interferon- $\gamma$; IL-4, interleukin-4; HIV, human immunodeficiency virus. 
fetal growth and development. Organisms face trade-offs in allocating resources between competing demands, such as survival, reproduction, and somatic maintenance, ${ }^{24,25}$ and these trade-offs may be especially exacerbated by the dual demands of simultaneous helminth infection and pregnancy. Moreover, helminth infections often occur in the context of coinfection with other parasites and pathogens, such as HIV, malaria, and giardia, ${ }^{26}$ and are most prevalent in areas where resources are scarce and nutrition may be limited. ${ }^{1,27}$

\section{Anemia during pregnancy}

Anemia is defined as low iron in the blood, typically measured in terms of hemoglobin concentration. Pregnancy is characterized by a decline in hemoglobin due primarily to hemodilution; as the total blood plasma volume increases, the number of erythrocytes per unit of blood declines. ${ }^{28}$ Hemoglobin varies across pregnancy, declining during the first and second trimesters, and improving or leveling off during the third trimester as the mother compensates for the added plasma volume. ${ }^{29}$ Guidelines for what constitutes anemia reflect this pattern, as anemia for pregnant women is defined by the World Health Organization as a hemoglobin concentration of $11 \mathrm{~g} / \mathrm{dL}$ versus $12 \mathrm{~g} / \mathrm{dL}$ for nonpregnant women. ${ }^{30}$ These normal changes in hemoglobin are not associated with adverse outcomes. In fact, women who do not experience pregnancy-related declines in hemoglobin or who have elevated hemoglobin have a higher risk of adverse outcomes, possibly due to a failure of plasma expansion. ${ }^{31,32}$

Anemia is one of the most common side effects of infection with geohelminths or schistosomes (Table 3), due to blood loss in the intestine or urinary tract. Hookworm, in particular, has been associated with moderate reductions in hemoglobin during pregnancy. ${ }^{33-38}$ Other geohelminths and schistosomes are associated with mild iron deficiency, but generally only when parasite burdens are high. ${ }^{33,34,36,39}$ However, there is little evidence to suggest a synergistic effect between infection and pregnancy; effects resemble those observed in nonpregnant women. Moreover, helminth infections alone are rarely associated with severe anemia in the absence of other confounding factors, such as nutritional deficiencies or coinfection with malaria or HIV. When nutritional deficiencies are present, helminths, and in particular hookworm, may exacerbate iron deficiency. ${ }^{36,37}$ Malaria coinfection is also associated with an increased risk of anemia and other negative outcomes during pregnancy, ${ }^{39,40}$ while the effects of helminths alone are often less clear. ${ }^{40}$

Unfortunately, there is a paucity of data examining whether helminth-induced anemia affects birth outcomes or infant health. Studies typically examine associations between helminths and anemia or anemia and birth outcomes, but have not examined whether birth outcomes differ with different causes of anemia. Severe anemia during pregnancy is associated with a number of adverse outcomes, including increased maternal mortality, ${ }^{41}$ increased risk of preterm birth or low birth weight, ${ }^{29,42,43}$ and increased risk of neonatal anemia. ${ }^{29,44}$ However, mild anemia is generally associated with limited risks during pregnancy. ${ }^{41,45}$ These results suggest that anemia due to helminths may only be of concern when worm burdens are high or when other factors contribute to anemia.

\section{Coinfection during pregnancy}

In addition to direct effects on mothers, helminths may affect coinfection risk or disease progression by biasing immunity or through other processes. To date, studies in pregnant women have primarily examined malaria and HIV, as these frequently co-occur in the populations in which helminth infections have been most frequently studied. In the case of malaria, interactions vary considerably by helminth species, parasite burden, and other factors. ${ }^{46}$ The fly-borne Mansonella perstans is associated with higher malaria parasitemia ${ }^{36}$ and prevalence. ${ }^{47}$ Mosquitoborne Wuchereria bancrofti has a more complex association with malaria, in part because the same mosquitos transmit both the helminth and Plasmodium falciparum parasites and high worm burdens can impact mosquitos, affecting the spread of malaria. ${ }^{48}$ A number of studies have found positive associations between geohelminths and malaria, suggesting that helminths may increase susceptibility, ${ }^{36,49,50}$ with the strongest evidence for an association with hookworm. ${ }^{40}$ Yet, some studies have also found that some species, such as A. lumbricoides, may be associated with reduced risk of malaria, ${ }^{51}$ and others have reported that infection with Schistosoma haematobium can limit parasitemia. ${ }^{46,52}$ In a randomized trial, treatment of helminths led to a short-term increase in malaria parasitemia, but with no long-term effects on malaria symptoms or prevalence. ${ }^{53}$ Thus, the actual effects of helminths on malaria coinfection remain somewhat unclear, as do any possible interactions with pregnancy.

A number of studies have examined coinfection between HIV and helminths in pregnant women. Both HIV and helminth infections can cause depletions in $\mathrm{CD}^{+} \mathrm{T}$-cells, ${ }^{54-58}$ and treatment of helminths reduces HIV progression and improves CD4 counts, although reductions in viral load may be small. ${ }^{59} \mathrm{At}$ least one study has found that helminths are associated with increased mother-to-infant transmission of HIV. ${ }^{60}$

\section{Premature birth and low birth weight}

A number of studies have found associations between helminths and lower birth weights; however, the majority of 
these studies have involved limited samples with comorbid conditions, and many have not used multivariate statistics to partition the effects of different helminth species or other contributing factors. In a study of HIV-infected women in Tanzania, helminth infections were associated with low birth weight, ${ }^{61}$ and another study in Nigeria found that helminth infections were associated with lower birth weight, but without isolating the effects of HIV status. ${ }^{62}$ Yatich et $\mathrm{al}^{39}$ found that in women with anemia, coinfection with helminths and malaria was associated with low birth weight, preterm delivery, and small birth weight for gestational age. Much of this effect appeared to be driven by malaria, as the only significant effect of helminths alone was an increase in the risk of being small for gestational age. A hospital-based study of Nigerian women found that helminth-malaria coinfection was associated with lower birth weight than malaria infection alone, but did not present data or make comparisons with uninfected women. ${ }^{63}$ A study conducted in Guatemala City found that helminth and protozoa were associated with risk of small birth weight for gestational age, but only in undernourished women, with undernourishment determined based on maternal height. ${ }^{64}$ In contrast to these studies, other studies of helminths alone have found no association between infection and birth weight ${ }^{65}$ or have actually found that women with infections have higher birth weights even in the presence of coinfections. ${ }^{66}$

\section{Perinatal mortality}

Few studies have directly measured whether infant mortality is affected by maternal infection during pregnancy. In a non-randomized study in which women were given albendazole, prenatal mortality was lower in the women who received treatment. ${ }^{67}$ A second study in Sri Lanka found that mebendazole was associated with reduced odds of stillbirth or perinatal death. ${ }^{68}$ However, neither study determined infection status either before or after treatment, and both may have been confounded by factors affecting which women received treatment in the first place. In three randomized trials, treatment had no significant effect on perinatal mortality. ${ }^{5,65,69,70}$

\section{Modulation of infant immune response}

In humans, there are scattered case reports suggesting that maternal-fetal transmission of infection may occasionally occur. ${ }^{71,72}$ Yet, these reports are rare, and on the whole, it appears that, for humans, helminths are rarely able to infect a developing fetus. However, several studies have found that helminth antigens are transferred to infants in utero. Evidence suggests that this occurs across a range of species, including filarial helminths, ${ }^{73-75}$ geohelminths,${ }^{76}$ and tremadodes.$^{77}$ As a consequence, infants whose mothers are infected during pregnancy show a variety of alterations in immunity, frequently characterized by increases in $\mathrm{T}_{\mathrm{H}} 2$ responses to helminth antigens and decreases in $T_{H} 1$ responses to nonhelminth antigens. ${ }^{78}$ For example, $W$. bancrofti infection during pregnancy is associated with changes in cytokine production in response to helminth antigens, as well as reductions in interferon (IFN)- $\gamma$ production in response to tuberculosis antigen. ${ }^{73,79,80}$ There is also evidence that infants with helminth-infected mothers are less likely to develop eczema, suggesting reductions in certain allergic responses. ${ }^{81,82}$ In many cases, these alterations resemble the effects of infection on adult immunity. ${ }^{77,78}$ However, in some cases, effects on infants have been found to be contrary to those in adults; that is, one study found that infants of mothers with hookworm showed increased IFN- $\gamma$ production to hookworm antigen, whereas their mothers had decreased IFN- $\gamma \cdot{ }^{76}$ While most studies have grouped all infants and measured average changes in immune function or resistance in children, a study by Malhotra et $\mathrm{al}^{74}$ took a different approach, and grouped infants of mothers with $W$. bancrofti based on whether their cord blood mononuclear cells showed a response to helminth antigen. Roughly half of the exposed newborns showed a response and were considered sensitized, while the other half did not respond and were considered tolerant. Tolerant infants were themselves more likely to become infected with $W$. bancrofti and had reduced IFN- $\gamma$ responses relative to sensitized or unexposed infants.

\section{The evolutionary context of antigen transmission and tolerance}

Most studies have implicitly considered the in utero transfer of antigen to infants to be a negative consequence of infection, with warnings that such transfers can induce tolerance or sensitization in the infant. The idea is that antigens transferred from the mother might be mistaken as self-antigens by the developing fetal immune system, and thus, responses to these antigens might be suppressed. Indeed, some evidence suggests that infants of infected mothers are at higher risk of infection, at least for filarial nematodes, including $W$. bancrofti and Onchocerca volvulus ${ }^{78,80,83,84}$ Some of these changes appear to persist for years, with effects documented as much as 19 years later. ${ }^{85}$

However, immunological tolerance may not always represent a negative outcome, despite the potential for higher prevalences of infection. In many instances, the most serious consequences of infections are caused not by the infections 
themselves, but by an overactive immune response to an infection. In the case of $W$. bancrofti, clinical disease such as elephantiasis develops in those with more hyperactive immune responses. Those with tolerant responses are often asymptomatic, despite being infected. ${ }^{86,87}$ Similarly, schistosomiasis is characterized by the formation of granulomas around schistosome eggs in the intestine or urinary tract, which accumulate to form physical blockages. The immunological profiles of those who develop disease differ from those who do not, with those developing disease having stronger responses to egg antigen. ${ }^{88}$

From an evolutionary perspective, immune responses always represent trade-offs between the costs of immunity and the benefits. ${ }^{89-91}$ Immune responses have both energetic and somatic costs from collateral damage. Thus, organisms have evolved to modulate immune responses when possible to avoid excess damage to self. Similarly, immune responses should be moderated when they are ineffective, or when the cost of clearing an infection outweighs the costs imposed by the infection itself. Under these circumstances, tolerance may represent the most adaptive host immunological strategy. ${ }^{18,19}$

Thus, an alternate hypothesis is that the tolerance induced by the maternal transfer of antigens to her infant represents an adaptive strategy. In support of this, most proteins cannot passively diffuse across the placental membrane, and so must be actively transported. ${ }^{92}$ This includes antibodies and antibody-antigen complexes, which are actively transported across the placental membrane. ${ }^{93-95}$ Moreover, transplacental immunization is not specific to helminths but is rather a much more general phenomenon. ${ }^{96-98}$ Thus, the maternal transfer of antigens is unlikely to be a consequence of manipulation by the parasite and more likely to represent an adaptation for preparing the immune system of the neonate to face pathogens present in the local environment. Infants who receive information from their mothers which conveys immunity, as well as information about the appropriate moderation of immune responses, might be expected to be at an advantage compared to infants born with completely naïve immune systems.

\section{Hypothetical interactions between helminths and pregnancy Fecundity and early pregnancy loss}

There are multiple pathways through which helminth infections might affect fecundity or lead to early loss of pregnancies, including redirection of resources, alteration of the hormonal milieu, ${ }^{20}$ or immunological biasing. ${ }^{4}$ However, there is little direct evidence. Anemia may affect egg maturation, leading to overall lower fecundity. ${ }^{29}$ Consistent with this, one study found that infection with hookworm was associated with both lower hemoglobin and a lower probability of a women becoming pregnant. ${ }^{4}$ The same study found that $A$. lumbricoides, which was not associated with anemia, was associated with an increased risk of becoming pregnant, perhaps due to immunological biasing toward an immunological environment favorable for a fetus. ${ }^{4}$

\section{Gestational diabetes}

We know of no studies testing whether helminth infections lead to complications such as gestational diabetes. However, helminth infections affect blood glucose, insulin resistance, and diabetes, leading to improved glucose tolerance and lower blood levels. ${ }^{99-104}$ Thus, helminths might also help modulate blood glucose during pregnancy. ${ }^{22}$ Helminth-induced anemia may also affect the risk of gestational diabetes, as excess iron during pregnancy is associated with increased risk of gestational diabetes. ${ }^{105}$

\section{Preeclampsia}

Preeclampsia is a complication of pregnancy characterized by hypertension, systemic inflammation, and increased protein in the urine. The symptoms of preeclampsia resemble tissue rejection of an immunologically distinct fetus. ${ }^{106-108}$ Indeed, a primary cause of preeclampsia is a mismatch between maternal killer immunoglobulin receptors and fetal HLA molecules. ${ }^{109}$ Given the immunological effects of helminths on maternal immunity, helminth infections might also affect preeclampsia, by increasing maternal tolerance of the fetus and by moderating inflammatory responses. Unfortunately, data addressing this hypothesis are currently lacking. However, such an effect might be behind the association between A. lumbricoides infection and increased fertility that we have previously reported. ${ }^{4}$

\section{Antihelminth treatment during pregnancy}

Given the complex interactions helminths can have on maternal and infant immune function, health, and coinfection risks, the question of whether helminths should be treated in pregnant women is far from straightforward. Initial studies established the safety of common helminth treatments, including albendazole, mebendazole, and praziquantel. These studies have generally found that treatment does not result in an increased prevalence of birth defects. ${ }^{65,68,110}$ However, these and additional studies have also found that treatment has limited effects on maternal and infant health. Both a meta-analysis conducted in $2012^{5}$ and a more recent 
Cochrane review ${ }^{6}$ found that antihelminth treatment had no clear overall effect on maternal anemia, low birth weight, or perinatal mortality. The 2012 review found a reduction in very low birth weight, but this was based only on one study with a significant effect and one without. ${ }^{5,69}$

What these meta-analyses may obscure is heterogeneity between study populations. Given the limited number of studies, it is difficult to ascertain whether antihelminth treatment might have beneficial effects under certain conditions and limited effects under others. For example, one study that found an effect of albendazole on maternal anemia also found that albendazole had far less effect than iron supplementation and had little effect when given alone. ${ }^{111}$ It may be that antihelminth treatment is only beneficial in women with very high parasite burdens, dietary insufficiencies, or both. In most instances when women are adequately nourished and burdens are low or moderate, treatment might have little effect.

Additional studies have examined whether helminth treatment during pregnancy affects infant immune responses. Several have found that treatment is associated with an increased incidence of eczema, suggesting that treatment may affect the development of mechanisms regulating infant immune responses. ${ }^{81,82,112}$ Others have examined whether treatment affects infant immune responses to helminth antigens. In general, infants of mothers who were infected but treated have similar immunological responses as infants of mothers infected but not treated. ${ }^{76,81,113}$ Treatment has also been found to have no significant effect on HIV transmission. ${ }^{113}$ However, given the limited scope of these trials, a number of questions remain regarding the effectiveness of treatment, the generalizability across helminth species, and possible effects dependent on the timing of treatment during pregnancy. ${ }^{114}$

\section{Conclusion: old enemies or old friends?}

Hosts and the organisms that live within them are constantly negotiating their relationships, both within individual lifetimes and over evolutionary time spans of many generations. Thus, these relationships are rarely settled, and the same organisms can impose costs or provide benefits to different individuals or in different contexts. Helminths are relatively long-lived organisms that depend on the survival of their hosts for continuous transmission. In this respect, helminths and their hosts share an interest in keeping the host alive and defending it against other competing pathogens and parasites. Unlike some other pathogens, such as viruses, for which humans develop effective immunity against particular strains, humans are also constantly reinfected by helminths, and transmission occurs largely within localized geographical areas. Thus, helminths may also benefit from maintaining reasonably healthy hosts that their descendants can continually infect. This history helps explain why the symptoms of helminth infections are often subtle and why human hosts frequently develop tolerant immune responses.

The difficulty of studying parasite interactions in natural settings means that many studies of helminths and pregnancy remain inconclusive. Confounding factors such as multiple comorbidities and small sample sizes make isolating the effects of particular species difficult, let alone elucidating the details on multispecies interactions. Future studies might provide more insight by using more sophisticated multivariate statistical approaches to partition variance and test explicit causal pathways, as opposed to simple associations which might be confounded by other variables. ${ }^{115}$

Despite these difficulties, some general conclusions can be drawn with regard to helminth infections during pregnancy. While comorbidities make separating effects difficult, there is sufficient evidence to suggest that some helminths are more harmful than others. Hookworm, for example, is found to cause anemia in pregnancy much more frequently than other geohelminths. As with most interactions of this kind, the evidence also suggests that conflicts of interest between host and parasite are most pronounced when resources are scarce. Helminths are more likely to be associated with negative outcomes when they occur with comorbid conditions, such as malaria or nutritional deficits. Yet in these cases, treating the comorbid condition may be more beneficial than treating the helminths. ${ }^{111}$ In the absence of such confounding factors or evidence of confounds, such as severe anemia, treatment may impose more costs than benefits, for example, by increasing the risk of infant eczema. Treatment may also have additional unanticipated effects by altering maternal blood glucose regulation, microbiota, or hormonal environment. Thus, broad efforts to treat all women should be approached with caution until future studies investigate these outcomes and how they play out under different ecological conditions.

\section{Acknowledgments}

The author thanks Richard McElreath and the Department of Human Behavior, Ecology, and Culture at the Max Planck Institute for Evolutionary Anthropology, Leipzig, Germany, for support during writing.

\section{Disclosure}

The author reports no conflicts of interest in this work. 


\section{References}

1. Hotez PJ, Brindley PJ, Bethony JM, King CH, Pearce EJ, Jacobson J. Helminth infections: the great neglected tropical diseases. J Clin Invest. 2008;118(4):1311-1321.

2. Maizels RM, Yazdanbakhsh M. Immune regulation by helminth parasites: cellular and molecular mechanisms. Nat Rev Immunol. 2003; 3(9): $733-744$.

3. Elliott AM, Ndibazza J, Mpairwe H, et al. Treatment with anthelminthics during pregnancy: what gains and what risks for the mother and child? Parasitology. 2011;138(12):1499-1507.

4. Blackwell AD, Tamayo MA, Beheim B, et al. Helminth infection, fecundity, and age of first pregnancy in women. Science. 2015;350(6263): 970-972.

5. Imhoff-Kunsch B, Briggs V. Antihelminthics in pregnancy and maternal, newborn and child health. Paediatr Perinat Epidemiol. 2012; 26 Suppl 1:223-238.

6. Salam RA, Haider BA, Humayun Q, Bhutta ZA. Effect of administration of antihelminthics for soil-transmitted helminths during pregnancy. Cochrane Database Syst Rev. 2015;(6):CD005547.

7. Brooker S, Bethony J, Hotez PJ. Human hookworm infection in the 21st century. Adv Parasitol. 2004;58:197-288.

8. O'Lorcain P, Holland CV. The public health importance of Ascaris lumbricoides. Parasitology. 2000;121 Suppl:S51-S71.

9. Greaves D, Coggle S, Pollard C, Aliyu SH, Moore EM. Strongyloides stercoralis infection. BMJ. 2013;347:f4610.

10. Stephenson LS, Holland CV, Cooper ES. The public health significance of Trichuris trichiura. Parasitology. 2000;121 Suppl:S73-S95.

11. Paily KP, Hoti SL, Das PK. A review of the complexity of biology of lymphatic filarial parasites. $J$ Parasit Dis. 2009;33(1-2):3-12.

12. Gryseels B, Polman K, Clerinx J, Kestens L. Human schistosomiasis. Lancet. 2006;368(9541):1106-1118.

13. Veenstra van Nieuwenhoven AL, Heineman MJ, Faas MM. The immunology of successful pregnancy. Hum Reprod Update. 2003; 9(4):347-357.

14. Shurin MR, Lu L, Kalinski P, Stewart-Akers AM, Lotze MT. Th1/Th2 balance in cancer, transplantation and pregnancy. Springer Semin Immunopathol. 1999;21(3):339-359.

15. Geiger SM, Massara CL, Bethony J, Soboslay PT, Carvalho OS, CorrêaOliveira R. Cellular responses and cytokine profiles in Ascaris lumbricoides and Trichuris trichiura infected patients. Parasite Immunol. 2002;24(11-12):499-509.

16. Wammes LJ, Hamid F, Wiria AE, et al. Regulatory T cells in human geohelminth infection suppress immune responses to BCG and Plasmodium falciparum. Eur J Immunol. 2010;40(2):437-442.

17. van Riet E, Hartgers FC, Yazdanbakhsh M. Chronic helminth infections induce immunomodulation: consequences and mechanisms. Immunobiology. 2007;212(6):475-490.

18. Medzhitov R, Schneider DS, Soares MP. Disease tolerance as a defense strategy. Science. 2012;335(6071):936-941.

19. Little TJ, Shuker DM, Colegrave N, Day T, Graham AL. The coevolution of virulence: tolerance in perspective. PLoS Pathog. 2010;6(9): e1001006.

20. Hernández-Bello R, Escobedo G, Guzmán C, Ibarra-Coronado EG, López-Griego L, Morales-Montor J. Immunoendocrine host-parasite interactions during helminth infections: from the basic knowledge to its possible therapeutic applications. Parasite Immunol. 2010;32(9-10): 633-643.

21. Pelletier F, Page KA, Ostiguy T, Festa-Bianchet M. Fecal counts of lungworm larvae and reproductive effort in bighorn sheep, Ovis canadensis. OIKOS. 2005;110(3):473-480.

22. Mpairwe H, Tweyongyere R, Elliott A. Pregnancy and helminth infections. Parasite Immunol. 2014;36(8):328-337.

23. Gonzalez-Fernandez D, Koski KG, Sinisterra OT, del Carmen Pons E, Murillo E, Scott ME. Interactions among urogenital, intestinal, skin, and oral infections in pregnant and lactating Panamanian Ngäbe women: a neglected public health challenge. Am J Trop Med Hyg. 2015;92(6):1100-1110.
24. Abrams ET, Miller EM. The roles of the immune system in women's reproduction: evolutionary constraints and life history trade-offs. Am J Phys Anthropol. 2011;146 Suppl 53:134-154.

25. Blackwell AD, Snodgrass JJ, Madimenos FC, Sugiyama LS. Life history, immune function, and intestinal helminths: trade-offs among immunoglobulin E, C-reactive protein, and growth in an Amazonian population. Am J Hum Biol. 2010;22(6):836-848.

26. Martin M, Blackwell AD, Gurven M, Kaplan H. Make new friends and keep the old? Parasite coinfection and comorbidity in Homo sapiens. In: Brinkworth JF, Pechenkina K, editors. Primates, Pathogens, and Evolution. New York: Springer; 2013:363-387.

27. Hotez PJ. Neglected infections of poverty in the United States of America. PLoS Negl Trop Dis. 2008;2(6):e256.

28. Goonewardene M, Shehata M, Hamad A. Anaemia in pregnancy. Best Pract Res Clin Obstet Gynaecol. 2012;26(1):3-24.

29. Miller EM. The reproductive ecology of iron in women. Am J Phys Anthropol. 2016;159(Suppl 61):S172-S195.

30. WHO. Haemoglobin Concentrations for the Diagnosis of Anaemia and Assessment of Severity. Geneva: World Health Organization; 2011.

31. Monika M, Sharma JB, Batra S, Sharma S, Murthy NS, Arora R. Maternal and perinatal outcome in varying degrees of anemia. Int $J$ Gynecol Obstet. 2002;79(2):93-100.

32. Scholl TO, Reilly T. Anemia, iron and pregnancy outcome. $J$ Nutr. 2000;130(2S Suppl):443S-447S.

33. Gyorkos TW, Gilbert NL, Larocque R, Casapía M. Trichuris and hookworm infections associated with anaemia during pregnancy. Trop Med Int Health. 2011;16(4):531-537.

34. Fuseini G, Edoh D, Kalifa BG, Hamid AW, Knight D. Parasitic infections and anaemia during pregnancy in the Kassena-Nankana district of Northern Ghana. J Public Health Epidemiol. 2010;2(3): $48-52$.

35. Larocque R, Casapia M, Gotuzzo E, Gyorkos T. Relationship between intensity of soil-transmitted helminth infections and anaemia during pregnancy. Am J Trop Med Hyg. 2005;73(4):783-789.

36. Muhangi L, Woodburn P, Omara M, et al. Associations between mild-to-moderate anaemia in pregnancy and helminth, malaria and HIV infection in Entebbe, Uganda. Trans R Soc Trop Med Hyg. 2007; 101(9):899-907.

37. Ndyomugyenyi R, Kabatereine N, Olsen A, Magnussen P. Malaria and hookworm infections in relation to haemoglobin and serum ferritin levels in pregnancy in Masindi district, western Uganda. Trans $R$ Soc Trop Med Hyg. 2008;102(2):130-136.

38. Nurdia DS, Sumarni S, Suyuko, Hakimi M, Winkvist A. Impact of intestinal helminth infection on anemia and iron status during pregnancy: a community based study in Indonesia. Southeast Asian J Trop Med Public Health. 2001;32(1):14-22.

39. Yatich NJ, Jolly PE, Funkhouser E, et al. The effect of malaria and intestinal helminth coinfection on birth outcomes in Kumasi, Ghana. Am J Trop Med Hyg. 2010;82(1):28-34.

40. Naing C, Whittaker MA, Nyunt-Wai V, et al. Malaria and soiltransmitted intestinal helminth co-infection and its effect on anemia: a meta-analysis. Trans R Soc Trop Med Hyg. 2013;107(11):672-683.

41. Brabin BJ, Hakimi M, Pelletier D. An analysis of anemia and pregnancy-related maternal mortality. $J$ Nutr. 2001;131(2S-2): 604S-615S; discussion 614S-615S.

42. Bánhidy F, Acs N, Puhó EH, Czeizel AE. Iron deficiency anemia: pregnancy outcomes with or without iron supplementation. Nutrition. 2011;27(1):65-72.

43. Levy A, Fraser D, Katz M, Mazor M, Sheiner E. Maternal anemia during pregnancy is an independent risk factor for low birthweight and preterm delivery. Eur J Obstet Gynecol Reprod Biol. 2005;122(2): 182-186.

44. Allen LH. Anemia and iron deficiency: effects on pregnancy outcome. Am J Clin Nutr. 2000;71(5 Suppl):1280S-1284S.

45. Lao TT, Pun TC. Anaemia in pregnancy - is the current definition meaningful? Eur J Obstet Gynecol Reprod Biol. 1996;68(1-2):53-58. 
46. Hartgers FC, Yazdanbakhsh M. Co-infection of helminths and malaria: modulation of the immune responses to malaria. Parasite Immunol. 2006; 28(10):497-506

47. Hillier SD, Booth M, Muhangi L, et al. Plasmodium falciparum and helminth coinfection in a semi-urban population of pregnant women in Uganda. J Infect Dis. 2008;198(6):920-927.

48. Muturi EJ, Jacob BG, Kim CH, Mbogo CM, Novak RJ. Are coinfections of malaria and filariasis of any epidemiological significance? Parasitol Res. 2008;102(2):175-181.

49. Yatich NJ, Yi J, Agbenyega T, et al. Malaria and intestinal helminth co-infection among pregnant women in Ghana: prevalence and risk factors. Am J Trop Med Hyg. 2009;80(6):896-901.

50. Adegnika AA, Ramharter M, Agnandji ST, et al. Epidemiology of parasitic co-infections during pregnancy in Lambaréné, Gabon. Trop Med Int Health. 2010;15(10):1204-1209.

51. Boel M, Carrara VI, Rijken M, et al. Complex interactions between soil-transmitted helminths and malaria in pregnant women on the ThaiBurmese border. PLoS Negl Trop Dis. 2010;4(11):e887.

52. Thigpen MC, Filler SJ, Kazembe PN, et al. Associations between peripheral Plasmodium falciparum malaria parasitemia, human immunodeficiency virus, and concurrent helminthic infection among pregnant women in Malawi. Am J Trop Med Hyg. 2011;84(3):379-385.

53. Wiria AE, Hamid F, Wammes LJ, et al. The effect of three-monthly albendazole treatment on malarial parasitemia and allergy: a householdbased cluster-randomized, double-blind, placebo-controlled trial. PLoS One. 2013;8(3):e57899.

54. Abdoli A, Pirestani M. Are pregnant women with chronic helminth infections more susceptible to congenital infections? Front Immunol 2014;5:53

55. Blackwell AD, Trumble BC, Maldonado Suarez I, et al. Immune function in Amazonian horticulturalists. Ann Hum Biol. 2016;43(4):382-396.

56. Borkow G, Leng Q, Weisman Z, et al. Chronic immune activation associated with intestinal helminth infections results in impaired signal transduction and anergy. J Clin Invest. 2000;106(8):1053-1060.

57. Kalinkovich A, Weisman Z, Greenberg Z, et al. Decreased CD4 and increased CD8 counts with $T$ cell activation is associated with chronic helminth infection. Clin Exp Immunol. 1998;114(3):414-421.

58. Tsegaye A, Wolday D, Otto S, et al. Immunophenotyping of blood lymphocytes at birth, during childhood, and during adulthood in HIV1-uninfected Ethiopians. Clin Immunol. 2003;109(3):338-346.

59. Means AR, Burns P, Sinclair D, Walson JL. Antihelminthics in helminth-endemic areas: effects on HIV disease progression. Cochrane Database Syst Rev. 2016;(4):1-61.

60. Gallagher M, Malhotra I, Mungai PL, et al. The effects of maternal helminth and malaria infections on mother-to-child HIV transmission. AIDS. 2005;19(16):1849-1855.

61. Dreyfuss ML, Msamanga GI, Spiegelman D, et al. Determinants of low birth weight among HIV-infected pregnant women in Tanzania. Am J Clin Nutr. 2001;74(6):814-826.

62. Aderoba AK, Iribhogbe OI, Olagbuji BN, Olokor OE, Ojide CK, Ande AB. Prevalence of helminth infestation during pregnancy and its association with maternal anemia and low birth weight. Int J Gynecol Obstet. 2015;129(3):199-202.

63. Egwunyenga AO, Ajayi JA, Nmorsi OPG, Duhlinska-Popova DD. Plasmodium/intestinal helminth co-infections among pregnant Nigerian women. Mem Inst Oswaldo Cruz. 2001;96(8):1055-1059.

64. Villar J, Klebanoff M, Kestler E. The effect on fetal growth of protozoan and helminthis infection during pregnancy. Obstet Gynecol. 1989; 74(6):915-920.

65. Ndibazza J, Muhangi L, Akishule D, et al. Effects of deworming during pregnancy on maternal and perinatal outcomes in Entebbe, Uganda: a randomized controlled trial. Clin Infect Dis. 2010;50(4):531-540.

66. Fairley JK, Bisanzio D, King CH, et al. Birthweight in offspring of mothers with high prevalence of helminth and malaria infection in coastal Kenya. Am J Trop Med Hyg. 2013;88(1):48-53.

67. Christian P, Khatry SK, West KP Jr. Antenatal anthelmintic treatment, birthweight, and infant survival in rural Nepal. Lancet. 2004;364(9438): 981-983.
68. de Silva NR, Sirisena JL, Gunasekera DP, Ismail MM, de Silva HJ Effect of mebendazole therapy during pregnancy on birth outcome. Lancet. 1999;353(9159):1145-1149.

69. Larocque R, Casapia M, Gotuzzo E, et al. A double-blind randomized controlled trial of antenatal mebendazole to reduce low birthweight in a hookworm-endemic area of Peru. Trop Med Int Health. 2006;11(10): 1485-1495.

70. Gyorkos TW, Larocque R, Casapia M, Gotuzzo E. Lack of risk of adverse birth outcomes after deworming in pregnant women. Pediatr Infect Dis J. 2006;25(9):791-794.

71. da Costa-Macedo LM, Rey L. Ascaris lumbricoides in neonate: evidence of congenital transmission of intestinal nematodes. Rev Inst Med Trop Sao Paulo. 1990;32(5):351-354.

72. Brinkmann UK, Krämer P, Presthus GT, Sawadogo B. Transmission in utero of microfilariae of Onchocerca volvulus. Bull World Health Organ. 1976;54(6):708-709.

73. Malhotra I, Mungai P, Wamachi A, et al. Helminth- and Bacillus Calmette-Guérin-induced immunity in children sensitized in utero to filariasis and schistosomiasis. J Immunol. 1999;162(11):6843-6848.

74. Malhotra I, Mungai PL, Wamachi AN, et al. Prenatal T cell immunity to Wuchereria bancrofti and its effect on filarial immunity and infection susceptibility during childhood. J Infect Dis. 2006;193(7): 1005-1013.

75. Elliott AM, Mawa PA, Webb EL, et al. Effects of maternal and infant co-infections, and of maternal immunisation, on the infant response to BCG and tetanus immunisation. Vaccine. 2010;29(2):247-255.

76. Elliott AM, Namujju PB, Mawa PA, et al. A randomised controlled trial of the effects of albendazole in pregnancy on maternal responses to mycobacterial antigens and infant responses to Bacille CalmetteGuérin (BCG) immunisation [ISRCTN32849447]. BMC Infect Dis. 2005;5(1):115.

77. Gebreegziabiher D, Desta K, Desalegn G, Howe R, Abebe M. The effect of maternal helminth infection on maternal and neonatal immune function and immunity to tuberculosis. PLoS One. 2014;9(4):e93429.

78. Elson LH, Days A, Calvopiña H, et al. In utero exposure to Onchocerca volvulus: relationship to subsequent infection intensity and cellular immune responsiveness. Infect Immun. 1996;64(12):5061-5065.

79. Malhotra I, Ouma J, Wamachi A, et al. In utero exposure to helminth and mycobacterial antigens generates cytokine responses similar to that observed in adults. J Clin Invest. 1997;99(7):1759-1766.

80. Malhotra I, Ouma JH, Wamachi A, et al. Influence of maternal filariasis on childhood infection and immunity to Wuchereria bancrofti in Kenya. Infect Immun. 2003;71(9):5231-5237.

81. Ndibazza J, Mpairwe H, Webb EL, et al. Impact of anthelminthic treatment in pregnancy and childhood on immunisations, infections and eczema in childhood: a randomised controlled trial. PLoS One. 2012;7(12):e50325.

82. Elliott AM, Mpairwe H, Quigley MA, et al. Helminth infection during pregnancy and development of infantile eczema. JAMA. 2005;294(16): 2032-2034.

83. Kirch AK, Duerr HP, Boatin B, et al. Impact of parental onchocerciasis and intensity of transmission on development and persistence of Onchocerca volvulus infection in offspring: an 18 year follow-up study. Parasitology. 2003;127(Pt 4):327-335.

84. Lammie PJ, Hitch WL, Walker Allen EM, Hightower AW, Eberhard ML. Maternal filarial infection as risk factor for infection in children. Lancet. 1991;337(8748):1005-1006.

85. Steel C, Guinea A, McCarthy JS, Ottesen EA. Long-term effect of prenatal exposure to maternal microfilaraemia on immune responsiveness to filarial parasite antigens. Lancet. 1994;343(8902):890-893.

86. Maizels RM, Lawrence RA. Immunological tolerance: the key feature in human filariasis? Parasitol Today. 1991;7(10):271-276.

87. Melrose WD. Lymphatic filariasis: new insights into an old disease. Int J Parasitol. 2002;32(8):947-960.

88. Caldas IR, Campi-Azevedo AC, Oliveira LF, Silveira AM, Oliveira RC, Gazzinelli G. Human schistosomiasis mansoni: immune responses during acute and chronic phases of the infection. Acta Trop. 2008; 108(2-3):109-117. 
89. McDade TW. Life history theory and the immune system: steps toward a human ecological immunology. Am J Phys Anthropol. 2003; 46:100-125.

90. Zuk M, Stoehr AM. Immune defense and host life history. Am Nat. 2002;160 Suppl 4:S9-S22.

91. Sheldon BC, Verhulst S. Ecological immunology: costly parasite defences and trade-offs in evolutionary ecology. Trends Ecol Evol. 1996; 11(8):317-321.

92. Gude NM, Roberts CT, Kalionis B, King RG. Growth and function of the normal human placenta. Thromb Res. 2004;114(5-6):397-407.

93. Malek A, Sager R, Schneider H. Transport of proteins across the human placenta. Am J Reprod Immunol. 1998;40(5):347-351.

94. May K, Grube M, Malhotra I, et al. Antibody-dependent transplacental transfer of malaria blood-stage antigen using a human ex vivo placental perfusion model. PLoS One. 2009;4(11):e7986.

95. Simister NE. Placental transport of immunoglobulin G. Vaccine. 2003; 21(24):3365-3369.

96. Gill TJ 3rd, Repetti CF, Metlay LA, et al. Transplacental immunization of the human fetus to tetanus by immunization of the mother. J Clin Invest. 1983;72(3):987-996.

97. Baker CJ, Rench MA, Edwards MS, Carpenter RJ, Hays BM, Kasper DL. Immunization of pregnant women with a polysaccharide vaccine of group B streptococcus. N Engl J Med. 1988;319(18): 1180-1185.

98. Holt PG, Jones CA. The development of the immune system during pregnancy and early life. Allergy. 2000;55(8):688-697.

99. Wiria AE, Hamid F, Wammes LJ, et al. Infection with soil-transmitted helminths is associated with increased insulin sensitivity. PLoS One. 2015;10(6): 0127746.

100. Wiria AE, Sartono E, Supali T, Yazdanbakhsh M. Helminth infections, type-2 immune response, and metabolic syndrome. PLoS Pathog. 2014; 10(7):e1004140.

101. Wu D, Molofsky AB, Liang HE, et al. Eosinophils sustain adipose alternatively activated macrophages associated with glucose homeostasis. Science. 2011;332(6026):243-247.

102. Yang Z, Grinchuk V, Smith A, et al. Parasitic nematode-induced modulation of body weight and associated metabolic dysfunction in mouse models of obesity. Infect Immun. 2013;81(6):1905-1914.

103. Chen Y, Lu J, Huang Y, et al. Association of previous schistosome infection with diabetes and metabolic syndrome: a cross-sectional study in rural China. J Clin Endocrinol Metab. 2013;98(2):283-287.

104. Gurven MD, Trumble BC, Stieglitz J, et al. Cardiovascular disease and type 2 diabetes in evolutionary perspective: a critical role for helminths? Evol Med Public Health. 2016:eow028.

105. Scholl TO. Iron status during pregnancy: setting the stage for mother and infant. Am J Clin Nutr. 2005;81(5):1218S-1222S.

106. Redman CW, Sargent IL. Latest advances in understanding preeclampsia. Science. 2005;308(5728):1592-1594.

107. Redman CW, Sacks GP, Sargent IL. Preeclampsia: an excessive maternal inflammatory response to pregnancy. Am J Obstet Gynecol. 1999; 180(2 I):499-506

108. Sacks GP, Studena K, Sargent K, Redman CW. Normal pregnancy and preeclampsia both produce inflammatory changes in peripheral blood leukocytes akin to those of sepsis. Am J Obstet Gynecol. 1998;179(1): 80-86.

109. Hiby SE, Walker JJ, O'shaughnessy KM, et al. Combinations of maternal KIR and fetal HLA-C genes influence the risk of preeclampsia and reproductive success. J Exp Med. 2004;200(8):957-965.

110. Friedman JF, Mital P, Kanzaria HK, Olds GR, Kurtis JD. Schistosomiasis and pregnancy. Trends Parasitol. 2007;23(4):159-164.

111. Torlesse H, Hodges M. Albendazole therapy and reduced decline in haemoglobin concentration during pregnancy (Sierra Leone). Trans R Soc Trop Med Hyg. 2001;95(2):195-201.
112. Mpairwe H, Webb EL, Muhangi L, et al. Anthelminthic treatment during pregnancy is associated with increased risk of infantile eczema: randomised-controlled trial results. Pediatr Allergy Immunol. 2011;22(3):305-312.

113. Webb EL, Mawa PA, Ndibazza J, et al. Effect of single-dose anthelmintic treatment during pregnancy on an infant's response to immunisation and on susceptibility to infectious diseases in infancy: a randomised, double-blind, placebo-controlled trial. Lancet. 2011;377(9759):52-62.

114. Yazdanbakhsh M, Luty AJ. Wormy mothers, healthy babies: case closed or conundrum? Lancet. 2011;377(9759):6-8.

115. Hellard E, Fouchet D, Vavre F, Pontier D. Parasite-parasite interactions in the wild: how to detect them? Trends Parasitol. 2015;31(12): 640-652.

116. Webb EL, Kyosiimire-Lugemwa J, Kizito D, et al. The effect of anthelmintic treatment during pregnancy on HIV plasma viral load: results from a randomized, double-blind, placebo-controlled trial in Uganda. J Acquir Immune Defic Syndr. 2012;60(3):307-313.

117. Blackwell AD, Martin M, Kaplan H, Gurven M. Antagonism between two intestinal parasites in humans: the importance of co-infection for infection risk and recovery dynamics. Proc Biol Sci. 2013;280(1769): 20131671.

118. Mireku MO, Boivin MJ, Davidson LL, et al. Impact of helminth infection during pregnancy on cognitive and motor functions of oneyear-old children. PLoS Negl Trop Dis. 2015;9(3):e0003463.

119. Ndibazza J, Webb EL, Lule S, et al. Associations between maternal helminth and malaria infections in pregnancy and clinical malaria in the offspring: a birth cohort in Entebbe, Uganda. J Infect Dis. 2013; 208(12):2007-2016.

120. Kawai K, Saathoff E, Antelman G, Msamanga G, Fawzi WW. Geophagy (soil-eating) in relation to anemia and helminth infection among HIV-infected pregnant women in Tanzania. Am J Trop Med Hyg. 2009;80(1):36-43.

121. Nielsen NO, Friis H, Magnussen P, Krarup H, Magesa S, Simonsen PE. Co-infection with subclinical HIV and Wuchereria bancrofti, and the role of malaria and hookworms, in adult Tanzanians: infection intensities, CD4/CD8 counts and cytokine responses. Trans $R$ Soc Trop Med Hyg. 2007;101(6):602-612.

122. Simonsen PE, Onapa AW, Asio SM. Mansonella perstans filariasis in Africa. Acta Trop. 2011;120 Suppl 1:S109-S120.

123. Ajanga A, Lwambo NJS, Blair L, Nyandindi U, Fenwick A, Brooker S. Schistosoma mansoni in pregnancy and associations with anaemia in northwest Tanzania. Trans R Soc Trop Med Hyg. 2006;100(1): 59-63.

124. La Flamme AC, Harvie M, Kenwright D, et al. Chronic exposure to schistosome eggs reduces serum cholesterol but has no effect on atherosclerotic lesion development. Parasite Immunol. 2007;29(5): 259-266.

125. Hamm DM, Agossou A, Gantin RG, et al. Coinfections with Schistosoma haematobium, Necator americanus, and Entamoeba histolytica/Entamoeba dispar in children: chemokine and cytokine responses and changes after antiparasite treatment. J Infect Dis. 2009;199(11):1583-1591.

126. Siegrist D, Siegrist-Obimpeh P. Schistosoma haematobium infection in pregnancy. Acta Trop. 1992;50(4):317-321.

127. Qunhua L, Jiawen Z, Bozhao L, et al. Investigation of association between female genital tract diseases and Schistosomiasis japonica infection. Acta Trop. 2000;77(2):179-183. 
International Journal of Women's Health

Dovepress

\section{Publish your work in this journal}

The International Journal of Women's Health is an international, peerreviewed open-access journal publishing original research, reports, editorials, reviews and commentaries on all aspects of women's healthcare including gynecology, obstetrics, and breast cancer. The manuscript management system is completely online and includes

Submit your manuscript here: http://www.dovepress.com/international-journal-of-womens-health-journa a very quick and fair peer-review system, which is all easy to use. Visit http://www.dovepress.com/testimonials.php to read real quotes from published authors. 